\title{
Heutagogy, Africanisation and Learning: Experiences from an Open and Distance Learning (ODL) Program at the University of South Africa
}

\author{
Vuyisile Msila \\ PO Box 392, College of Education, University of South Africa, UNISA, 0003, South Africa
}

\section{Doi:10.5901/mjss.2014.v5n14p214}

\begin{abstract}
Currently the aspirant African university constantly seeks to foster relevance as it develops into the 21st century. Many African universities have begun debating about the possibilities of Africanising the curricula as they face the tide of globalization. To African intellectuals, it has become important to perceive the relevance of the African experience. However, it is not always easy to harmonize the Western experience and the African experience. This qualitative study looked at a new open and distance learning (ODL) module just introduced at the University of South Africa's (UNISA's) College of Education. The module applies the modes of heutagogy which emphasize self-determined learning. A sample of 15 students was interviewed using semi-structured interviews. The students highlighted nearness between African models and the signature module's (under study) mode of delivery. Sharing of experiences, democratic education and being conscious of the local experiences were among the factors perceived by the participants as akin to African models.
\end{abstract}

Keywords: Emancipatory learning. Self-directed learning. Afro-centric theory. Western theories. globalization.

\section{Introduction: New Ways of Learning in Higher Education}

The new heutagogical open and distance Learning (ODL) module- Being a Professional Teacher, at the University of South Africa (UNISA) heralds ways in which the future ODL programs will be run. The ODL this century will be transformed by the emerging online practices linked to technology-based programs. Blaschke (2012) points out that heutagogy is a form of self-determined learning with practices that are rooted in andragogy. "Educators today are tasked with developing lifelong learners who can survive and thrive in a global knowledge economy" (Blaschke 2012:57). Furthermore, this author distinguishes between andragogy (self-directed learning) and heutagogy (self-determined learning). Heutagogy is a practice-based approach that has built on the experiences of experiential learning of andragogy. Turner (2012) points out that the educator in a heutagogical environment facilitates the learning process through guidance and by providing resources. Furthermore, he contends that unlike in andragogy, in a heutagogical environment, the facilitator expedites the learning process through guidance and by providing resources. The universities today want to prepare future citizens who will be critical beings in society.

Among others the $21^{\text {st }}$ century learner needs the following skills:

- To be able to take charge of their own learning;

- While enhancing their independence, they should also be able to function meaningfully with others;

- Use technology to better their lives, others as well as improving their surroundings; and

- Attaining competency and being able to use creativity to sustain themselves.

All these are part of heutagogically based models. Heick (2013) points out that with the progress of technology and the rise in mobile learning; self-directed learning is a natural choice.

Pascarella and Umbach (2012) also point out that one particular goal of higher education is the development of critical thinking skills. Students who frequently report on their positive empowerment are those who are critical thinkers. In a country where examiners are usually concerned with student cheating in examinations, it will help if the examinations would test critical thinking rather than rote learning or memory recall. Teacher training programs need to stress critical thinking because it is through empowered teachers that society can have critical learners in schools. Duran and Sendag (2012) opine that critical thinking is based on relating and drawing conclusions on notions and events. Furthermore, these authors say it involves different cognitive processes such as implicating problem solving, reflecting and criticizing. All these are skills necessary to live in today's world. Duran and Sendag (2012: 241) aver:

Thinking begins with a physical or psychological inconvenience stemming from lacking the solution for a problem whose solution becomes the objective for an individual. Higher order thinking skills, like critical thinking and problem 
solving are considered necessary skills for 21 st century individuals.

All education institutions should be using these skills. Learners need higher order thinking skills if education is to make any sense. Shannon and Bennett (2012) cite a number of authors who observed that critical thinking evolves with the following stages:

- Apply - The students use knowledge and understanding to complete a practical task;

- Analyze -While working on a practical task, the students break things down into their component parts;

- Synthesize - The students then will be able to combine and integrate various sources of information; and

- Evaluate - At the end of the task completion, the students will be able to assess the value, merit or worth of something.

Facione (2013) also emphasizes critical thinking in education. He posits:

\begin{abstract}
After years of viewing higher education as more of a private good which benefits only the student, we are again beginning to appreciate higher education as being also a public good which benefits society. It is not a wiser social policy to invest in the education of the future workforce, rather than to suffer the financial costs and endure the fiscal; and social burdens associated with economic weakness, public health problems, crime, and avoidable poverty?
\end{abstract}

Facione argues that higher education institutions should help people make good decisions. They should be contributing members of society rather than burdens. Heutagogy seeks to create this critical citizen who will be beneficial to society.

Turner (2012) also contends that unlike in andragogy, in a heutagogical environment the educator gives up control of the learning path; for the learners determine their path and set their own learning goals. Rodger (2012:2) states that a heutagogical approach gives the students the opportunity to determine:

- The scope and goals of their learning;

- The resources and processes by which they will learn;

- The ways in which their learning will be evaluated; and

- The evidence that will be produced to be evaluated.

Using these strategies the heutagogical student develops an ability to be critical and be self-motivated to learn.

In search of harmonization between Western and African models, this study sought to explore whether heutagogy can be linked to Africanisation philosophy and theories. African intellectuals are in quest for contexts that would not alienate the African student from the content of the curriculum. This study then posed the main question among heutagogical students from UNISA's signature module: How do the students in a heutagogical program perceive the role of African theories in the delivery of their module?

How can they make use of potential aspects in this program?

\title{
2. Objectives of the study
}

This study seeks to investigate the following objectives:

- To investigate which aspects of the heutagogical module at UNISA show African contexts;

- To explore how students can maximize the use of heutagogy's delivery modes (within the African context); and

- To explore the role that can be played by heutagogy and African models to emancipate students as critical thinkers.

\section{Africanising the Curriculum}

The new campuses in Africa are looking at the need to globalize and Africanise. While universities globalize, they also need to accommodate the local context. In Africa one can speak of Africanising the curriculum in ODL institutions such as UNISA. Makgoba (1997:203) refers to Africanisation "as the process or vehicle for defining, interpreting, promoting and transmitting African thought, philosophy, identity and culture". This definition is supported by Seepe (2004:10) who contends, "Africanisation of knowledge and (Indigenous Knowledge Systems) IKS are an antidote to centuries of denigration of people's knowledges. Africanisation of knowledge and IKS places the African world-view at the centre of analysis". In this article this is how this concept will be understood and in studying heutagogy and its possible nearness to Africanisation, it will be understood in this context.

This article also seeks to use an Afrocentric analysis in looking at heutagogy. It seeks to illustrate how intellectuals 
can use the African paradigm in understanding higher education in Africa. If Africans seek cultural justice that would oppose cultural hegemony of Western education, the starting point should be to understand the role of Africanisation in education. There is much that intellectuals can benefit from the African world-view. The Africans need an education system where they can recognize their identities and cultures. Many systems that are completely Eurocentric in approach fail to reflect these (African) identities. This article consciously sought to find a way for intellectuals to tease out an African context in education. Woldegiorgis (2013) points out that one of the challenges of applying certain theories to other contexts such as Africa is that from the outset, these theories are created within the context of Europe. This article then sought to search for that harmonization of a UNISA program with Africanisation.

Waghid (2004) raises an interesting argument about the implications of African philosophy of education for teaching and learning. In line with the signature module discussed here, Waghid (2004:61) argues:

\begin{abstract}
African philosophy of education with its emphasis on achieving reasonableness would be inclined towards an approach to teaching and learning whereby students, for instance, abandon the expectation that prescribed texts and course readings be considered as master texts- students are regarded as reasonable people, which means they become more open to interpreting, analysing and looking beyond texts.
\end{abstract}

The above accommodates heutagogy which purports self-determined learning. This kind of philosophy might be daunting for facilitators whose paradigm still operates in the past. These are facilitators who are used to talk over the students not to them. African philosophy is inherently inclusive in approach and there is always the belief that everyone can bring something to the "village". In education context, this translates into critical pedagogy where all students are potential carriers of knowledge. Waghid (2004) again points out that the African philosophy of education has a potential to enhance efficacy of teaching and learning in university classrooms.

\title{
4. Research Methodology
}

The signature module under study is in its first year at the University of South Africa (2013). The students come from all over the country although the researcher randomly selected 15 from a given list. All those selected are from the Gauteng Province area where the university is situated. Therefore, the researcher used convenience sampling. The characteristics of the population were mostly homogenous. They did not have a teaching qualification, they had grade 12 as the highest school qualification. This homogeneity enabled the researcher to use convenience sampling. Struwig and Stead (2004) define convenient sampling as sampling chosen purely on the basis of availability. Participants are selected because they are accessible and articulate. Each of the fifteen participants was interviewed and observed as they worked on some of their online activities. Out of this 15 , only four were initially computer literate. The questions though were not focused on their ability to use internet but on their perceptions of the module as helping them towards the attainment of African values within ODL. The researcher initially furnished definitions of terms that had a potential to confuse the participants. It was crucial for example, for the participants to understand what Africanisation meant within the context of the study.

The researchers gave each participant the transcript after an interview session to verify answers. In addition to the 15 students, three online tutors of the module were interviewed. The tutors were mainly asked about their perceptions of the signature module. The interviews for both the students and the tutors were semi-standardized interviewees. The semi-standardized interview is a combination of the structured and unstructured interviews (Struwig and Stead 2004). Predetermined questions were posed but the participants were given the opportunity to discuss issues beyond the determined questions.

\section{The Findings and Discussion}

\subsection{Sharing of experiences: An African obligation}

Sharing is among the cornerstones of Africanisation. Educational practices have been like this in Africa for many epochs. Education within the African context reflects communalism where the people will soon realize the success of any member of the village is dependent upon the success of the other members of the clan. Even when an elder teaches a child on the traditions of the clan he hopes and wishes that the oral account will be passed to a larger audience by the perceiver. Van Wyk and Higgs (2004:206) aptly put this when they state that traditional African educational thought is characterized "not only by its concern with the person, but also its interweaving of social, economic, political, cultural, and educational threads together in a common tapestry". Van Wyk and Higgs add by pointing that education in Africa attaches a collective 
and social nature and is very close to communal life. The module under discussion reflects these elements because through it the collective experiences, number of registered students share experiences and acquire skills. "The emphasis on communalism...in traditional African thought and experience also requires higher education in the African context to pay attention to interpersonal and interactive skills" (Van Wyk and Higgs 2004:206).

Van Niekerk (2004) also spells out the role of community in open and distance learning. He points out that in ODL people should not create an environment that brings forth a culture of teacher dependence but rather one that promotes independent and co-dependent learning. Furthermore, he contends (Van Niekerk 2004: 196):

\begin{abstract}
In establishing communities of learning the teacher as facilitator will have to devise cooperative learning strategies and foster a collaborative environment that discourages a teacher-dependent attitude. The teacher's task would be to create a context for learning and to be a mediator in developing a learning culture and establishing a community of learning.
\end{abstract}

The students and their online tutors concurred that one of the basic necessities of the online signature module was the sharing of ideas by the students. The learning in the program was always initiated by students' engagement in activities. Students work in groups and each group is built by discussions. These are started by individuals and others respond and this is where the sharing of ideas grows. The module coordinator followed the students' discussions just to see whether learning is continuing or not. The tutors also pointed out that the assignments they marked were group projects that reflected ideas shared by the students in their respective groups. The students benefited in that each shared experiences that others did not necessarily have. It was for example interesting to see a thread in discussion of rural teachers and teachers based in urban areas. Some of the aspects that urban teachers took for granted were usually absent luxuries in the rural schools. Some rural teachers in their groups shared how their schools did not have running water, science laboratories and the necessary equipment. There were several teachers in the urban areas who did not even think that some of these would not be present in their schools. The sharing of experiences made others to experience their peers' world. This was crucial because some city based teachers might teach in rural schools in future. It also makes teachers to see a much broader world of teaching than only looking into their own.

This sharing of experiences is a true reflection of the African village. The module coordinator, like the village chief, waits to hear from the villagers as to what needs to be done. The coordinator leads in a democratic fashion as she listens and follows the groups' discussions. This is the only way that she can help each group develop. For effective learning to occur each member of the group has to participate effectively. The module coordinator for assessment looks at the contributions of each member. The study group, like a group of villagers will only be as effective as the contribution of its members. The village leader will be as strong as the unity in the villagers' bond. The new ODL programs that require student initiative will thrive when the students work closely with one another and with their module coordinator. This new ODL model is unlike the earlier models that promoted competition and selfishness. More openness is promoted by heutagogical models. In a group one will not learn effectively if some members of one's group are not contributing. The experiences of all are crucial. This promotes democratic learning as well.

\title{
5.2 Democratic learning: Each one teaching the other
}

Democracy is one of the central aspects in post-apartheid education in South Africa. This system is based on the Constitution of the Republic which seeks to achieve social justice. This democratic system envisages critical learners and critical educators. It is interesting to see how the students understood their module as advancing critical learning and democratic principles. These democratic approaches were crucial in addressing past inequalities where education was a vehicle to undermine other groups especially black Africans. Critical education opposes inferiority and is a remedy to education that promotes learners who are docile. African philosophies of education are for this critical reflection. Osman (2004) argues that critical adult education has always wanted to influence equity and justice in a democratic society. Furthermore, he says critical education connects with the material realities of ordinary people's lives.

The greatest form of democracy that the students felt within the program was the module's ability to accommodate their background and identities. They found doing the module emancipatory because they were able to use own examples as they expressed their identities. As seen from the above the learning in a heutagogical setting the sharing of experiences is essential for learning to take place. This means that each person learns from the other. This is the effective aspect in transformational learning. The students in the pilot study underscored their learning from one another. The module coordinator, the chief in the village does not tell them what to do. The villagers learn from one another. One who knows poisonous snakes, good berries, and a good place to hunt will inform the others. In turn these will teach others as well. This is the kind of transformational learning necessary in effective ODL classes today. The teacher is no 
longer the one who generates knowledge because learning is bottom up. The facilitator, as pointed out above is guided by the discussions of the students in her virtual classroom. All students are given equal chance to deliberate in group discussions. The heutagogical module models these democratic principles which are part of the African village. The democratic principle on which this learning is based empowers the students involved. Teachers who have undergone this kind of training will be empowered to face the challenges of educators.

This democratic principle does not only reflect the principle in an African village but it also reflects what the current post-apartheid education system in South Africa demands. The students in South Africa just like their educators are supposed to embrace a new kind of outlook, and new roles. The education policy documents postulate that learners need to be:

- Confident and independent

- Literate, numerate and multi-skilled

- Compassionate, with respect for the environment and an ability to participate in society as a critical and active citizen.

The students in the signature module also need to embrace these qualities espoused in policy documents. With this emphasis on empowerment of the learners, it is clear that policy makers see education as a means of transforming the society. The latter is positive considering the struggles waged in South Africa to attain a democratic state that would open up opportunities of education for all. Teacher education becomes crucial in this regard because if ODL in South Africa is to be deemed successful it will have to support democratic education. Democratic education of teachers is one more aspect that would ensure that new teachers will in turn teach democracy and social justice in their classrooms. Arguably, people cannot talk of empowered learners when their teachers are not. As countries in the sub-Saharan Africa are trying to improve retention of learners in basic education, teacher education needs to be improved together with the quality of education. Verspoor (2008:29) argues:

The classroom is where inputs are transformed into learning. Without a competent teacher no curriculum can be implemented effectively. In sub-Saharan Africa, improving teaching practice will require changes in the traditional rote learning methods that still dominate the vast majority of classrooms. Efforts to shift instructional practice towards open ended approaches, such as child-centred, activity-oriented teaching, have been difficult to implement throughout the world.

The post-apartheid curriculum poses challenges to teachers and learners alike. Sometimes with no resources at home. No parental guidance and uninviting classrooms the majority of learners (especially from historically black schools) do not find education purposeful. Teachers on the other hand might feel ill-prepared for the new constructivist approaches and teach the way in which they were taught.

\subsection{Relevance: studying the local}

Usually education is dominated by cultural hegemony where the students study through another culture or another perspective rather than their own. This cultural domination is perceived through the use of aspects such as language, methods, content and curriculum. However, what the participants highlighted in this study was the relevance and the strength of studying the local aspects of education. They also pointed out that they were much stronger in the module because they learnt about experiences they knew. Many stated that they were used to system that brought content that was not reflecting what they saw every day. The examples from the module were probing into what they knew. The tutors also echoed the sentiments of the students by stating that the content of the module presented material that was familiar to the students' world of experience. This is the essence of an Africanised system of education; a system in Africa that reflects the African experience.

Louw (2010:45) points out:

It is clear that the time has come to rethink the local content of subject areas. By changing the curriculum in accordance with societal needs, we will change the way in which teaching and learning are constructed. Vilakazi $(2000,196)$ warns that there is an urgent need for education and development policies to be synchronized, and for a specific local curriculum with appropriate knowledge to be designed. A restructured higher education curriculum is therefore needed, where African reality is taken seriously alongside Western ideas.

The role of the signature module is to achieve exactly this; to ensure that higher education uses what the students experience from their environment. Furthermore, Louw sees this as the direction that higher education in Africa needs to 
take as he argues that it needs to focus on the rebirth of an African voice and identity. Learning about a relevant African experience in Africa leads to the emancipation of the students. The relevant content empowers and frees the students who get to understand and be proud of who and where they are. Nkoane (2006) succinctly captures the need to for students to be committed African intellectuals. "Afrocentric education seeks to foster in its learners an African consciousness and behavioural orientation which will optimize the positive expression of African learners' fundamental humanity and ability to contribute significantly to the total growth and development of the African community of which an African learner is a member" (Nkoane 2006: 50). The students in the signature module at UNISA also stated that they were aware of the need to enrich their teaching knowledge by utilizing what they have gone through in life and what they have experienced in their surroundings. The approaches the students are able to use make them develop their professional consciousness as they try to solve the challenges in African classrooms.

\section{Conclusion}

This study showed that the online students perceived aspects that can be linked to the African experience. It also shows that this experience frees them from the throes of studying content using a Western view that is so removed from their own experience. The African consciousness instilled by Africanisation in students emancipates the way they view the professional life of the teacher. This was crucial for the students under study because they will soon qualify to be teachers in various African settings. Knowing the consciousness of the local communities will make these teachers to face the teaching world with confidence and passion. Teachers need this emancipator pedagogy where they would clearly see their future role in teaching. In fact, all teacher education programs in Africa should be able to reflect the students' future experience in schools. Starting from the relevant surrounding will always feed the teacher with the necessary confidence. ODL institutions in Africa should be in the lead in ensuring that higher education liberates and empowers future teachers.

\section{Recommendations}

At the completion of this study three recommendations were drawn for teacher training institutions. These have to do with relevance in teacher training programs, learning in an "African village" of groups and emancipating student teachers by ensuring that they discover learning from their environment on their own than teaching them set aims and objectives. Below, I briefly discuss each.

The first recommendation is the need for teacher education institutions to strengthen relevance of their curricula. When students are offered relevant curricula they see a purpose in their studies and gain commitment to the teaching profession. All faculties should ensure that their programs are able to reflect the students' environment. Relevance of curricula gives meaning to the student and the module coordinators alike. In class discussions students cherish talking about the environment they are used to.

Secondly, teacher training programs should instil a culture of group work. Teachers are usually isolated when they are in schools working. The culture in schools tends to be against teachers working together. Yet, teacher training faculties should elevate group work because this is where teachers will share invaluable experiences. Teacher training programs should also make sure that teacher collaboration is modelled by the manner in which the program is delivered. In the program under study, it was clear that the module's success was dependent upon teacher collaboration.

Finally, the aspects of Africanisation in the signature module liberated the students' minds. Having to create knowledge enriched the students' pedagogical skills as well as their ability to be critical thinkers. The idea of an African consciousness as well as relevance opens up the possibilities of being a critical practitioner.

\section{References}

Blaschke, L.M. (2012). Heutagogy and Lifelong Learning: A review of heutagogical practice and self-determined Learning. The International Review of Research in Open and Distance Learning, 13(1): 56-71.

Duran, M., \& Sendag, S. (2012). A preliminary investigation into critical thinking skills of urban high schools students: Role of an IT/STEM Program. Creative Education, 3(2): 241-250.

Facione, P.A. (2013). "Critical thinking: What it is and why it counts" Insight Assessment: 1-28.

Heick, T. (2013) A primer in heutagogy and self-directed learning. [Online] Available http//www.teacherthought.com/learning/a-primer-inheutagogy-and-self-directed-learning. (February, 12, 2014)

Louw, W. (2010). Africanisation: A rich environment for active learning on a global platform. Progressio, 32 (1):42-54.

Makgoba, M.W. (1997). Mokoko: The Makgoba affair: Reflection on Transformation. Bel Air: Vivlia. 
Nkoane, M.M. (2006). The Africanisation of the university in Africa. Alternation, 13 (1): 49- 69.

Rodgers, R. (2012). Pedagogy...Andragogy...Heutagogy! The next step in Adult Learning. Catalyst, 30 (March): 1-2.

Osman, R. (2004). Making the Invisible Visible: Portfolios and Prior Knowledge in Higher Education. South African Journal of Higher Education, 18(3): 305-315.

Pascarella E.T., \& Blaich, C. (2012). Lessons from the Wabash national study of Liberal arts.

Education. Change - The Magazine of Higher Learning, 45(2):6-15.

Seepe, S. (2004). Editorial. South African Journal of Higher Education, 18(3):9-16.

Shannon, L., \& Bennett, J. (2012). A case study: applying critical thinking to Computer Science and Technology. Information Systems Education Journal, 10 (4): 41-48.

Struwig, F.W., \& Stead, G.B. (2004). Planning, designing and reporting research. Cape Town: Pearson Education.

Turner, J.R. (2012). Training \& Learning Theories: Pedagogy, Andragogy. Heutagogy. [Online] http://johnturnerhptresource. blogspot.com/2012/07/training-learning-theories-pedagogy.html. (May 27, 2013).

Van Niekerk, L. (2004). Distance education as a function of community. South African Journal of Higher Education, 18(3): 185-195.

Van Wyk, B., \& Higgs, P. (2004). Towards an African Philosophy of Higher Education. South African Journal of Higher Education, 18(3): 196-210.

Verspoor, A. (2008). At the Crossroads, Choices for Secondary Education in Sub- Saharan Africa. Washington: World Bank.

Waghid, Y. (2004). African Philosophy of Education: Implications for Teaching and Learning. South African Journal of Higher Education, 18(3): 56-64.

Woldegiorgis, E.T. (2013). Conceptualising harmonisation of higher education systems: the application of Regional integration theories on Higher Education Studies. Higher Education Studies, 3 (2): 12- 23. 